\title{
Risk Factors Affecting Transient Tachypnea of the Newborn in Fatemieh Hospital of Hamadan, Iran, 2015 - 2016
}

\author{
Mohammad Kazem Sabzehei ${ }^{1}$, Behnaz Basiri ${ }^{1,{ }^{*}}$, Maryam Shokouhi ${ }^{1}$, Afshin Fayyazi ${ }^{1}$ and Fatemeh \\ Eghbalian $^{1}$
}

${ }^{1}$ Department of Pediatrics, Hamadan University of Medical Sciences, Hamadan, IR Iran

"Corresponding author: Department of Pediatrics, Hamadan University of Medical Sciences, Hamadan, Iran. Tel: +98-8138278080, Fax: +98-8138262151, E-mail: behnazbasiri@yahoo.com

Received 2017 June 25; Revised 2017 September 17; Accepted 2017 November 18.

\begin{abstract}
Background: Transient tachypnea of the newborn (TTN) is one of the important causes of neonatal respiratory distress and hospitalization in the neonatal intensive care unit (NICU).

Objectives: The current study aimed at identifying the risk factors of TTN in a single tertiary care center.

Methods: The current prospective, case-control study was conducted on 180 newborns allocated in the 2 groups of with TTN ( $\mathrm{n}=90$ ) as the case group, and without TTN $(n=90)$ as the control group for 1 year from April to March 2015 in a public hospital of Hamadan, Iran. Newborn and mother's information was extracted from their medical records. Diagnosis of TTN was based on clinical and radiological findings, after ruling out other respiratory distress causes. Data were analyzed using logistic regression and $\mathrm{P}<0.05$ was considered the level of significance.

Results: The raw data analysis of regression factors associated with TTN showed that the risk of TTN was higher in late preterm infants (odds ratio (OR): 6.15 ; $95 \%$ confidence interval $(\mathrm{CI}): 3.17-11.92, \mathrm{P}=0.001$ ) as well as male newborns (OR: $0.33,95 \% \mathrm{CI}$ : 0.17- 0.62, $\mathrm{P}=0.001)$, and those born by cesarean $(\mathrm{OR}: 11.22,95 \% \mathrm{CI}: 5.33-23.62, \mathrm{P}=0.001)$. Moreover, the risk of TTN increased with Apgar score in the first minute(OR: 0.02.95\% CI: $0.00-0.05, \mathrm{P}=0.001)$ and decreased with the fifth minute (OR: $0.02 ; 95 \%$ CI: 0.00 $-0.06, P=0.001)$. The results of multiple regression analysis showed that the odds of TTN of late preterm newborns was 2.96 times higher than that of term newborns (OR: 2.96, 95\% CI: 1.09- 8.04, P = 0.033). Furthermore, with increase in Apgar score in the first minute, the risk of TTN reduced (OR: $0.02 ; 95 \%$ CI: $0.01-0.07$, P = 0.001). Conclusions: Prematurity and Apgar score in the first minute were the risk factors for TTN. Consequently, the risk of TTN can be reduced by the prevention of preterm birth and improvement of perinatal care.
\end{abstract}

Keywords: Transient Tachypnea of Newborn, Risk Factors, Apgar Score

\section{Background}

Transient tachypnea of the newborn (TTN) is one of the major causes of neonatal respiratory distress. It is a parenchymal lung disorder created due to delayed absorption of fetal lung fluid. TTN occurs in $1-3 \%$ of the all births; TTN presents in the early hours of life and usually improves within 24 to 72 hours, but some of the affected infants rarely develop sever respiratory distress, which indicate malignant TTN (1-4).

Tachypnea is the most common clinical manifestation of the disease, but other symptoms such as cyanosis, nasal flaring, intercostal muscle retraction, and grunting are also observed. In chest X-ray, lung hyperinflation with flattening of the diaphragm, mild cardiomegaly, and prominent pulmonary vascular markings in hilum are also detected. Ultrasonography is introduced recently to diagnose the disease (5). Prematurity and elective cesarean before 39 weeks are the most significant risk factors associated with TTN and other risk factors of the disease include male gender, maternal diabetes, maternal asthma, macrosomia, and perinatal asphyxia (6-10).

\section{Objectives}

Identifying and preventing the risk factors of TTN result in lower incidence of the disease and its complications. There are a few studies in the developing countries on the risk factors of TTN; therefore, the current study aimed at identifying these factors in a tertiary care center in Iran for 1 year.

\section{Methods}

\subsection{Study Subjects}

The current prospective, case-control study was carried out for 1 year from April to March 2015 in Fatemieh hospital affiliated to Hamadan University of Medical Sciences, Hamadan, Iran. The hospital has a 33-bed level III neonatal intensive care unit (NICU) with more than 95\% inborn admissions and about 6000 deliveries per year.

All infants delivered and admitted to NICU due to respiratory distress following the diagnosis of TTN were enrolled in the study as the case group and the same number of non-affected infants was selected as the control group. 
Infants with a gestational age of less than 34 weeks, congenital heart disease, congenital anomalies, and neonates with respiratory distress not diagnosed with TTN were excluded. Patients' data including neonatal birth weight, gestational age, gender, delivery mode, amniotic fluid color, Apgar score of the first and fifth minutes after birth, maternal disease, and disease outcome were extracted from mother and infant's medical records.

The following neonatal diagnostic criteria were used: Gestational age was defined based on prenatal ultrasonography or the time of the last menstrual period (LMP). Apgar score was performed on a newborn at 1 and 5 minutes after birth. TNN was diagnosed by neonatologist based on medical history, clinical signs, and chest X-rays findings, after ruling out of respiratory (such as meconium aspiration syndrome, respiratory distress syndrome, and pneumonia) and non-respiratory (such as polycythemia and hypoglycemia) complications causing tachypnea in newborns.

\subsection{Sample Size}

The sample size was set to 90 patients in each group using a sampling formula according to the study by Derbent et al. The following formula was employed to calculate the sample size.

$n=\frac{\left(Z_{1-\frac{\alpha}{2}}+Z_{1-\beta}\right)^{2}\left(\sigma_{1}^{2}+\sigma_{2}^{2}\right)}{\left(\mu_{1}-\mu_{2}\right)^{2}}$

$\alpha=0.05, \beta=20 \%, \sigma_{1}=870, \sigma_{2}=630, \mu_{1}=2810, \mu_{2}=3265$, $\mathrm{n}=58.57$

\subsection{Statistical Analysis}

Statistical analyses were conducted with SPSS version 16 (SPSS Inc, Chicago, IL). Data were expressed as range and mean \pm standard deviation (SD)/ or numbers and percentages. The chi-square and tests were used to compare the risk factors between the affected and non-affected groups, and logistic regression analysis was used for multivariate analyses. The confidence interval level was set to $95 \%$.

\subsection{Ethical Considerations}

The current study was approved by the ethics committee of the Hamadan University of Medical Sciences. The consent was obtained from parents of the infants with a full explanation of the study objectives and methods.

\section{Results}

In the present study, 180 newborns including 90 newborns with TTN (the case group) and 90 infants nonaffected with TTN (the control group) were investigated for the possible risk factors. Most of the infants with TTN were male (73.3\%), late preterm (62.2\%), and born by cesarean section (86.6\%). Mean gestational age, mean birth weight, and mean Apgar scores in first and fifth minutes after birth in infants with TTN were lower than those without TTN (Table 1).

The raw data analysis of the regression factors associated with TTN showed that in late preterm infants, the risk of TTN was 6.15 times higher than that of the term birth infants (odds ratio (OR): 6.15; 95\% confidence interval (CI): 3.17 - 11.92, $\mathrm{P}=0.0010)$. Moreover, in female newborns, the risk of TTN was 0.67 times higher than the male infants (OR: 0.33, 95\% CI: 0.17 - 0.62, $\mathrm{P}=0.001$ ); in infants delivered by cesarean section the risk of TTN was 11.22 times higher than the ones delivered vaginally (OR: 11.22, 95\% CI: 5.33 23.62, $\mathrm{P}=0.001)$. In addition, the risk of TTN was lower in the infants with higher Apgar scores in the first (OR: 0.02, 95\% CI: $0.00-0.05 ; \mathrm{P}=0.001)$ and fifth (OR: 0.02; 95\% CI: 0.00 - $0.06 ; \mathrm{P}=0.001)$ minutes. However, there was no significant correlation between amniotic fluid color, neonatal birth weight, history of maternal diabetes, preeclampsia, and TTN $(\mathrm{P}>0.05)$ (Table 2).

The results of multiple regression analysis showed that the odds of TTN in the late preterm newborns was 2.96 times higher than that of the term newborns (OR: 2.96; 95\% $\mathrm{CI}: 1.09$ - 8.04; $\mathrm{P}=0.033)$. Moreover, with increase in Apgar score in the first minute, the risk of TTN reduced (OR: 0.02 ; 95\% CI: $0.01-0.07, \mathrm{P}=0.001$ ) (Table 3).

\section{Discussion}

The current study results were in line with those of other studies regarding a significant relationship between Apgar score in the first minute and TTN in infants $(11,12)$. The possible mechanism of the low Apgar score effect on delayed lung fluid absorption can be the impairment in the regulation of catecholamines, capillary leak syndrome pulmonary edema, and myocardial dysfunction associated with an increase in filling pressure (12).

Moreover, the results of the current study showed a direct correlation between late preterm delivery and the incidence of TTN. Other studies also showed that with 1 week increase in gestational age, the incidence of neonatal respiratory distress is reduced twice (8), and prematurity is a major risk factor for $\operatorname{TTN}(6,12,13)$. Furthermore, respiratory complications in late preterm infants is 4.4 times higher than term infants (14); the reason can be explained by the physiological events of the last weeks of pregnancy, which with the onset of spontaneous labor cause hormonal changes in the mother and the fetus and makes the fetus ready to enter the neonatal period. Increase in endogenous steroids and catecholamine occur when fetus 


\begin{tabular}{|c|c|c|c|c|}
\hline \multirow[t]{2}{*}{ Characteristic } & \multirow[t]{2}{*}{ Total } & \multicolumn{2}{|c|}{ Transient Tachypnea of Newborn } & \multirow[t]{2}{*}{ P Value } \\
\hline & & Case & Control & \\
\hline Gender & & & & 0.000 \\
\hline Male & $109(60.6)$ & $66(73.3)$ & $43(47.8)$ & \\
\hline Plurality & & & & 0.033 \\
\hline Single tone & $172(95.6)$ & $83(92.2)$ & $89(98.9)$ & \\
\hline Multiple & $8(4.4)$ & $7(7.8)$ & $1(1.1)$ & \\
\hline Amniotic fluid & & & & 0.064 \\
\hline Clear & $164(91.1)$ & $83(92.2)$ & $81(90.0)$ & \\
\hline Meconium staining & $16(8.9)$ & $7(7.8)$ & $9(10.0)$ & \\
\hline Gestational age & & & & 0.000 \\
\hline Late preterm & $75(41.7)$ & $56(62.2)$ & $19(21.1)$ & \\
\hline Term & $105(58.3)$ & $34(37.8)$ & $71(78.9)$ & \\
\hline Maternal disease & & & & 0.001 \\
\hline None & $123(69.9)$ & $73(82.0)$ & $50(57.5)$ & \\
\hline PROM & $46(26.1)$ & $11(12.4)$ & $35(40.2)$ & \\
\hline Preeclampsia and diabetes & $7(4.0)$ & $5(5.6)$ & $2(2.3)$ & \\
\hline Birth weight & & & & 0.008 \\
\hline Normal & $150(83.3)$ & $71(78.9)$ & $79(87.8)$ & \\
\hline$\leq 2500 \mathrm{~g}$ & $30(16.7)$ & $19(21.1)$ & $11(12.2)$ & \\
\hline NVD & $69(38.3)$ & $12(13.3)$ & $57(63.3)$ & \\
\hline Cesarean & $111(61.7)$ & $78(86.7)$ & $33(36.7)$ & \\
\hline
\end{tabular}

${ }^{\mathrm{a}}$ Values are expressed as No. (\%).

reaches to full term and vaginal delivery; the factors affecting lung maturation. Fetal lung fluid clearance is carried out by the absorption of trans-epithelial sodium through sodium-sensitive channels in alveolar epithelial cells. Disturbance of this process can lead to fluid retention in the lung and alveolar hypoventilation. In preterm birth, especially in cesarean delivery, before the onset of spontaneous labor, the infant often deals with hormone change complications, resulting in a more difficult transitional period and increased risk of TTN (15).

The results of the current study showed that infants born with gestational age of 34 to 39 weeks by caesarean section are significantly at higher risk for TTN compared with those born by vaginal delivery; the results were consistent with those of the study by Riskin et al. They studied 67 newborns with TTN and gestational age of $>35$ weeks. In their study, the mean gestational age was lower and the rate of caesarean section was higher among newborns with TTN. According to the results of their study, gesta- tional age $<38$ weeks and elective caesarean section (ECS) were associated with the risk of TTN (13). In the studies by Limlikhit and Mostafa Hefny on newborns delivered by cesarean section and vaginal method, the risk of TTN was 2 and 1.5 times higher than those of their controls, respectively $(16,17)$. The results of Silasi et al., also showed that caesarean section generally was a risk factor for TTN and cesarean section before the onset of labor had no impact on the inhibition of TTN in newborns (18). However, in other studies on 36-week-old infants with respiratory distress, it was suggested that cesarean section before the onset of labor might be beneficial $(19,20)$. Therefore, based on the association between newborn respiratory problems and high frequency of cesarean section before the week 39, which result in newborn's hospitalization in NICU (21-23), to reduce TTN incidence in infants, it is recommended that obstetrician give full awareness to mothers about the risk of cesarean section, especially at a lower gestational age and get the mother's consent for the elective cesarean be- 


\begin{tabular}{|c|c|c|c|}
\hline Characteristic & OR & 95\% CI & PValue \\
\hline \multicolumn{4}{|l|}{ Gestational age } \\
\hline Term & - & - & - \\
\hline Late preterm & 6.15 & $3.17-11.92$ & 0.001 \\
\hline \multicolumn{4}{|l|}{ Gender } \\
\hline Male & - & - & - \\
\hline Female & 0.33 & $0.17-0.62$ & 0.001 \\
\hline Apgar score at minute 1 & 0.02 & $0.00-0.05$ & 0.001 \\
\hline Apgar score at minute 5 & 0.02 & $0.00-0.06$ & 0.001 \\
\hline \multicolumn{4}{|l|}{ Birth weight } \\
\hline Normal & - & - & - \\
\hline$\leq 2500 \mathrm{~g}$ & 1.92 & $0.85-4.31$ & 0.113 \\
\hline \multicolumn{4}{|l|}{ Delivery mode } \\
\hline NVD & - & - & - \\
\hline Cesarean & 11.22 & $5.33-23.62$ & 0.001 \\
\hline \multicolumn{4}{|l|}{ Plurality } \\
\hline Single tone & - & - & - \\
\hline Multiple & 7.50 & $0.90-62.31$ & 0.062 \\
\hline \multicolumn{4}{|l|}{ Maternal disease } \\
\hline None & - & - & - \\
\hline PROM & 0.21 & $0.10-0.46$ & 0.001 \\
\hline Preeclampsia and diabetes & 1.71 & $0.32-9.17$ & 0.530 \\
\hline \multicolumn{4}{|c|}{ Table 3. Multivariate Logistic Regression Analysis } \\
\hline Characteristic & $\mathbf{O R}$ & 95\% CI & P Value \\
\hline \multicolumn{4}{|l|}{ Gestational age } \\
\hline Term & - & - & - \\
\hline Preterm & 2.96 & $1.09-8.04$ & 0.033 \\
\hline Apgar score at minute 1 & 0.02 & $0.01-0.07$ & 0.001 \\
\hline
\end{tabular}

fore 39 weeks of pregnancy (24).

In the current study, most of the newborns with TTN were male. The odds of developing TTN in male newborns were higher than that of females; similar to the results of other studies $(20,25,26)$.

In the study, contrary to other studies, there was no significant relationship between amniotic fluid color, neonatal birth weight, history of maternal diabetes, preeclampsia, and TTN (6-10), which can be explained by the assessment of various risk factors in different studies.

\subsection{Study limitations}

The study was conducted in a single tertiary care center with small number of cases, and therefore, the authors suggest further research with a larger sample size in order to elucidate factors contributing TTN.

\subsection{Conclusion}

The results of the current study indicated that lower gestational age and lower Apgar score were the risk factors for TTN. Consequently, prevention of preterm birth and improvement of perinatal care can reduce the risk of TTN.

\section{Acknowledgments}

The study was extracted from PhD dissertation of Mahdi Keshavarz. Hereby, the authors acknowledge their gratitude to him for his valuable contribution, as well as NICU nursing staff, and medical records department personnel of Fatemieh hospital for their cooperation with the study.

\section{Footnotes}

Authors' Contribution: Study concept and design, Mohammad Kazem Sabzehei; acquisition of data, Behnaz Basiri and Maryam Shokouhi; analysis and interpretation of data, Afshin Fayyazi; drafting of the manuscript, Maryam Shokouhi and Behnaz Basiri; critical revision of the manuscript for important intellectual content, Behnaz Basiri and Mohammad Kazem Sabzehei; statistical analysis, Fayyazi; administrative, technical, and material support, Fatemeh Eghbalian and Maryam Shokouhi; study supervision, Mohammad Kazem Sabzehei.

Conflict of Interests: It was not declared by the authors.

Ethical Approval: The current study was approved by the ethics committee of the Hamadan University of Medical Sciences.

Financial Disclosure: Authors declared no financial disclosure regarding the materials and results of the study.

Funding/Support: It was not declared by the authors.

Informed Consent: The consent was obtained from parents of the infants with a full explanation of the study objectives and methods.

\section{References}

1. Aathi MK. Transient Tachypnea of Newborn (TTN): An Overview. Int J NurEdu Res. 2014;2(2):99-103.

2. Hermansen CL, Lorah KN. Respiratory distress in the newborn. Am Fam Physician. 2007;76(7):987-94. [PubMed: 17956068].

3. Jain L, Dudell GG. Respiratory transition in infants delivered by cesarean section. Semin Perinatol. 2006;30(5):296-304. doi: 10.1053/j.semperi.2006.07.011. [PubMed: 17011402]. 
4. El Farargy MS, Soliman NA. Early Predictors of Transient Tachypnea of Newborn. J Mol Biomark Diagn. 2017;8(2). doi: 10.4172/21559929.1000317.

5. Liu J, Chen XX, Li XW, Chen SW, Wang Y, Fu W. Lung Ultrasonography to Diagnose Transient Tachypnea of the Newborn. Chest. 2016;149(5):1269-75. doi: 10.1016/j.chest.2015.12.024. [PubMed 26836942].

6. Derbent A, Tatli MM, Duran M, Tonbul A, Kafali H, Akyol M, et al. Transient tachypnea of the newborn: effects of labor and delivery type in term and preterm pregnancies. Arch Gynecol Obstet. 2011;283(5):94751. doi: 10.1007/s00404-010-1473-6. [PubMed: 20431892].

7. Tutdibi E, Gries K, Bucheler M, Misselwitz B, Schlosser RL, Gortner L. Impact of labor on outcomes in transient tachypnea of the newborn: population-based study. Pediatrics. 2010;125(3):e577-83. doi: 10.1542/peds.2009-0314. [PubMed: 20156904].

8. Kolas T, Saugstad OD, Daltveit AK, Nilsen ST, Oian P. Planned cesarean versus planned vaginal delivery at term: comparison of newborn infant outcomes. Am J Obstet Gynecol. 2006;195(6):1538-43. doi: 10.1016/j.ajog.2006.05.005. [PubMed:16846577].

9. Badran EF, Abdalgani MM, Al-Lawama MA, Al-Ammouri IA, Basha AS, Al Kazaleh FA, et al. Effects of perinatal risk factors on common neonatal respiratory morbidities beyond 36 weeks of gestation. Saudi Med J 2012;33(12):1317-23. [PubMed: 23232680].

10. Birnkrant DJ, Picone C, Markowitz W, El Khwad M, Shen WH, Tafari N. Association of transient tachypnea of the newborn and childhood asthma. Pediatr Pulmonol. 2006;41(10):978-84. doi: 10.1002/ppul.20481. [PubMed: 16871596].

11. Perez Molina JJ, Romero DM, Ramirez Valdivia JM, Corona MQ. [Transient tachypnea of the newborn, obstetric and neonatal risk factors] Ginecol Obstet Mex. 2006;74(2):95-103. [PubMed:16637378].

12. Takaya A, Igarashi M, Nakajima M, Miyake H, Shima Y, Suzuki S. Risk factors for transient tachypnea of the newborn in infants delivered vaginally at 37 weeks or later. J Nippon Med Sch. 2008;75(5):269-73. doi: 10.1272/jnms.75.269. [PubMed: 19023165].

13. Riskin A, Abend-Weinger M, Riskin-Mashiah S, Kugelman A, Bader D. Cesarean section, gestational age, and transient tachypnea of the newborn: timing is the key. Am J Perinatol. 2005;22(7):377-82. doi: 10.1055/s-2005-872594. [PubMed:16215925].

14. Khashu M, Narayanan M, Bhargava S, Osiovich H. Perinatal outcomes associated with preterm birth at 33 to 36 weeks' gestation: a population-based cohort study. Pediatrics. 2009;123(1):109-13. doi 10.1542/peds.2007-3743. [PubMed:19117868].
15. Jain L, Eaton DC. Physiology of fetal lung fluid clearance and the effect of labor. Semin Perinatol. 2006;30(1):34-43. doi: 10.1053/j.semperi.2006.01.006. [PubMed: 16549212].

16. Limlikhit T. Risk factors of transient tachypnia of the newborn in detudom crown Prince hospital. Mahasarakham Hosp J. 2015;12(2):59-68.

17. Mostafa Hefny S, Mohammed Taher Hashem A, Ahmed Abdel-Razek AR, Mohammed Ayad S. The neonatal respiratory outcome in relation to timing of elective cesarean section at 38 versus 39week gestation: A single center based study. Egyptian Pediatric Association Gaz. 2013;61(2):78-82. doi:10.1016/j.epag.2013.06.001.

18. Silasi M, Coonrod DV, Kim M, Drachman D. Transient tachypnea of the newborn: is labor prior to cesarean delivery protective? Am J Perinatol. 2010;27(10):797-802. doi: 10.1055/s-0030-1254549. [PubMed: 20486067].

19. Cohen M, Carson BS. Respiratory morbidity benefit of awaiting onset of labor after elective cesarean section. Obstet Gynecol.1985;65(6):81824. doi:10.1097/00132582-198512000-00012. [PubMed: 4000571].

20. Guglani L, Ryan R, Lakshminrusimha S. Risk factors and management of transient tachypnea of the newborn. Pediatr Health. 2009;3(3):25160

21. Tita AT, Landon MB, Spong CY, Lai Y, Leveno KJ, Varner MW, et al. Timing of elective repeat cesarean delivery at term and neonatal outcomes. N Engl J Med. 2009;360(2):111-20. doi:10.1056/NEJMoa0803267. [PubMed: 19129525].

22. Glavind J, Uldbjerg N. Elective cesarean delivery at 38 and 39 weeks: neonatal and maternal risks. Curr Opin Obstet Gynecol. 2015;27(2):1217. doi: 10.1097/GCO.0000000000000158. [PubMed: 25689238].

23. Tita AT, Lai Y, Landon MB, Spong CY, Leveno KJ, Varner MW, et al. Timing of elective repeat cesarean delivery at term and maternal perioperative outcomes. Obstet Gynecol. 2011;117(2 Pt 1):280-6. doi: 10.1097/AOG.0b013e3182078115. [PubMed: 21252740].

24. Mould TA, Chong S, Spencer JA, Gallivan S. Women's involvement with the decision preceding their caesarean section and their degree of satisfaction. Br J Obstet Gynaecol. 1996;103(11):1074-7. doi: 10.1111/j.14710528.1996.tb09585.x. [PubMed: 8916991].

25. Liem JJ, Huq SI, Ekuma O, Becker AB, Kozyrskyj AL. Transient tachypnea of the newborn may be an early clinical manifestation of wheezing symptoms. J Pediatr. 2007;151(1):29-33. doi: 10.1016/j.jpeds.2007.02.021. [PubMed: 17586187].

26. Kheir AM, Ahmed TA. Prevalence, risk factors and short term outcome of infants with transient tachypnea of the newborn in sudan. Eur J Pharm Med Res. 2016;3(10):23-6. 